12 Marmot MG, Smith GD, Stansfeld S, Patel C, North F, Head J, et al. Health inequalities among British civil servants: the Whitehall II study. Lancet 1991;337:1387-93.

13 Marmot MG, Bosma H, Hemingway H, Brunner E, Stansfeld S. Contribution of job control and other risk factors to social variations in coronary heart disease incidence. Lancet 1997·350.235-9.

14 Pais P, Pogue J, Gerstein H, Zachariah E, Savitha D, Jayprakash S, et al. Risk factors for acute myocardial infarction in Indians: a case-control study. Lancet 1996;348:358-63.

15 Japanese Ministry of Health and Welfare. Special report of vital statistics in 1990. Occupational and industrial aspects. Tokyo: Health and Welfare Statistics Association, 1994.

16 Alfredsson L, Hammar N, Hogstedt C. Incidence of myocardial infarction and mortality from specific causes among bus drivers in Sweden. Int J and mortality from specifin

17 Stender M, Hense HW, Doring A, Keil U. Physical activity at work and cardiovascular disease risk: results from the MONICA Augsburg study. Int J Epidemiol 1993;22:644-50.

18 Appels A, Schouten E. Burnout as a risk factor for coronary heart disease. Behav Med 1991;17:53-9.

19 Tuomilehto J, Salonen JT, Marti B, Jalkanen L, Puska P, Nissinen A, et al. Body weight and risk of myocardial infarction and death in the adult population of eastern Finland. BMJ 1987;295:623-7.

20 Hosmer DW, Lemeshow S. Applied logistic regression. New York: John Wiley and Sons, 1989.

21 SAS Institute. Conditional logistic regression for m:n matching. In: SAS/ STAT software:changes and enhancements through release 6.11. Cary, NC: SAS Institute, 1996.

22 Hayashi T, Kobayashi Y, Yamaoka K, Yano E. Effect of overtime work on 24-hour ambulatory blood pressure. J Occup Environ Med 1996;38: 1007-11.
23 Pieper C, Warren K, Pickering TG. A comparison of ambulatory blood pressure and heart rate at home and work on work and non-work days. $J$ Hypertens 1993;11:177-83.

24 Hayano J, Sakakibara Y, Yamada M, Ohte N, Fujinami T, Yokoyama K, et al. Decreased magnitude of heart rate spectral components in coronary artery disease. Its relation to angiographic severity. Circulation 1990;81:1217-24.

25 Hayano J, Yamada A, Mukai S, Sakakibara Y, Yamada M. Severity of coronary atherosclerosis correlates with the respiratory component of heart rate variability. Am Heart J 1991;121:1070-9.

26 Mukai S, Hayano J. Heart rate and blood pressure variabilities during graded head-up tilt. J Appl Physiol 1995;78:212-6.

27 Kageyama T, Nishikido N, Kobayashi T, Kurokawa Y, Kabuto M. Commuting, overtime, and cardiac autonomic activity in Tokyo. Lancet 1997;350:639.

28 Christensen NJ, Jensen EW. Sympathoadrenal activity and psychosocial stress. The significance of aging, long-term smoking, and stress models. Ann N Y Acad Sci 1995;771:640-7.

29 Havano J, Yamada M, Sakakibara Y, Fujinami T, Yokovama K, Watanabe Y, et al. Short- and long-term effects of cigarette smoking on heart rate variability. Am J Cardiol 1990;65:84-8.

30 Muscat JE, Wynder EL. Exposure to environmental tobacco smoke and the risk of heart attack. Int J Epidemiol 1995;24:715-9.

31 Hammond SK, Sorensen G, Youngstrom R, Ockene JK. Occupational exposure to environmental tobacco smoke. JAMA 1995;274:956-60.

32 Morris JK, Cook DG, Shaper AG. Loss of employment and mortality. BMJ 1994;308:1135-9.

(Accepted 8 June 1998)
South Cleveland

Hospital,

Middlesbrough

TS4 3BW

P N Gordon,

senior house officer in

intensive care

S Williamson,

senior registrar in

anaesthetics

P G Lawler,

consultant in

intensive care

Correspondence to:

Dr P N Gordon,

Department of

Obstetrics an

Gynaecology, South

Cleveland Hospital,

Middlesbrough

TS4 3BW

patrickg@

globalnet.co.uk

BMJ 1998;317:780-3

\title{
As seen on TV: observational study of cardiopulmonary resuscitation in British television medical dramas
}

\author{
P N Gordon, S Williamson, P G Lawler
}

\begin{abstract}
Objective: To determine the frequency and accuracy with which cardiopulmonary resuscitation is portrayed in British television medical dramas. Design: Observational study.

Subjects: 64 episodes of three major British television medical dramas: Casualty, Cardiac Arrest, and Medics.

Main outcome measures: Frequency of cardiopulmonary resuscitation shown on television; age, sex, and diagnosis of the patients undergoing resuscitation; rate of survival through resuscitation. Results: Overall 52 patients had a cardiorespiratory arrest on screen and 3 had a respiratory arrest alone, all the arrests occurring in 40 of the 64 episodes. Of the 52 patients having cardiorespiratory arrest, 32 $(62 \%)$ underwent an attempt at cardiopulmonary resuscitation; 8 attempts were successful. All 3 of the patients having respiratory arrests alone received ventilatory support and survived. On $48 \%$ of occasions, victims of cardiac arrest seemed to be less than 35 years old.

Conclusions: Cardiorespiratory resuscitation is often depicted in British television medical dramas. Patients portrayed receiving resuscitation are likely to be in a younger age group than in real life. Though the reasons for resuscitation are more varied and more often associated with trauma than in reality, the overall success rate is nevertheless realistic. Widespread overoptimism of patients for survival after resuscitation cannot necessarily be blamed on British television medical dramas.
\end{abstract}

\section{Introduction}

Since Kouwenhoven's original description of modern cardiopulmonary resuscitation $^{1}$ and the obvious early successes of the technique, ${ }^{2}$ resuscitation has become increasingly commonplace in hospitals and the community. The advent of prompt resuscitation and the ready availability of intensive care has produced moral dilemmas about the appropriateness of resuscitation in some patients and in some situations. Until recently it has been common hospital practice for most end of life decisions that concern resuscitation or the institution of intensive care in hospital patients to be taken by the clinicians in charge of the individual's care. ${ }^{3}$ In recent years there has been a move towards more open discussion about end of life decisions with patients and their families, often in advance preparation for critical illness and with a view to making living wills or advance directives.

It has been recognised that patients, their relatives, and the doctors and nurses responsible for their care often have an unrealistically optimistic impression of the effectiveness of resuscitation. ${ }^{5-7}$ Furthermore it has been shown that patients' perception of the likelihood of success of resuscitation has a strong effect on their desire for resuscitation or intensive care in the event of their own critical illness. ${ }^{8}$ The public's knowledge of complex medical issues such as resuscitation is becoming increasingly sophisticated, and the factors influencing this knowledge are many and varied. Information may come from personal experience or from external sources, including life support training programmes, newspaper and magazine journalism, and television 
Table 1 Cardiopulmonary resuscitation in British television medical dramas

\begin{tabular}{lccc} 
& No of & \multicolumn{2}{c}{ No of arrests } \\
\cline { 3 - 4 } Programme & 26 & 18 & 2 \\
\hline Casualty & 27 & 29 & 0 \\
\hline Cardiac Arrest & 11 & 5 & 1 \\
\hline Medics & 64 & 52 & 3
\end{tabular}

\begin{tabular}{|c|c|c|c|}
\hline \multicolumn{2}{|c|}{ No $(\%)$ of resuscitation attempts } & \multicolumn{2}{|c|}{ No $(\%)$ of survivors } \\
\hline Cardiac arrests & Respiratory arrests & Cardiac arrests & Respiratory arrests \\
\hline $11(61)$ & 2 & $1(9)$ & 2 \\
\hline $16(55)$ & 0 & $5(31)$ & 0 \\
\hline $5(100)$ & 1 & $2(40)$ & 1 \\
\hline $32(62)$ & 3 & $8(25)$ & 3 \\
\hline
\end{tabular}

news and drama. Several studies have found that most people say that television is their primary source of information and education about resuscitation. ${ }^{6} 1011$

We aimed to find out how cardiopulmonary resuscitation is portrayed in British television medical dramas in order to help analyse the role television might play in influencing the public's view of resuscitation and its effectiveness.

\section{Method}

We contacted the television companies responsible for the production of three major television medical dramas-Casualty (BBC), Cardiac Arrest (World Productions), and Medics (Granada)-and arranged to view videos of a selection of the most recently broadcast programmes. We watched 26 episodes of Casualty (series X, episodes 1-14; series XI, episodes 1-12), all 27 episodes of Cardiac Arrest (series 1, 2, and 3), and 11 episodes of Medics (series 4, episodes 29-39). We identified each occurrence of cardiac arrest (defined as an event in which a person is seen to die, stop breathing, or develop an arrhythmia not compatible with life) or where the person is said by one of the characters on screen to be having an arrest. We also identified each time an attempt at cardiac massage or artificial ventilation was made to resuscitate an arrested patient. We recorded the patients' apparent or stated age and, when possible, the stated or apparent cause of the cardiac arrest. We noted whether the resuscitation attempt seemed to be successful in the short term and (if shown) in the longer term. The programmes were watched by one of two viewers (PG and SW) and the information documented on a standard data sheet. Several episodes were viewed by both investigators to help standardisation, and any uncertain cases were discussed.

For each programme we calculated the frequency of cardiac arrest and of resuscitation attempts. We examined the demography of the patients on television and the circumstances precipitating the arrest to assess the degree of realism.

\section{Programmes}

Casualty (BBC) is set in the accident and emergency department of a district general hospital. Episodes usually develop several storylines and end in a scenario involving the department. The work and personal relationships of the main characters, the hospital staff, are developed from episode to episode. A wide range of clinical conditions is portrayed with a high degree of accuracy and realism, and political and ethical issues often arise. The programme is shown at peak viewing time and attracts about 14 million viewers per episode.

Cardiac Arrest (World Productions) ran to three series, each episode attracting about 8 million viewers.

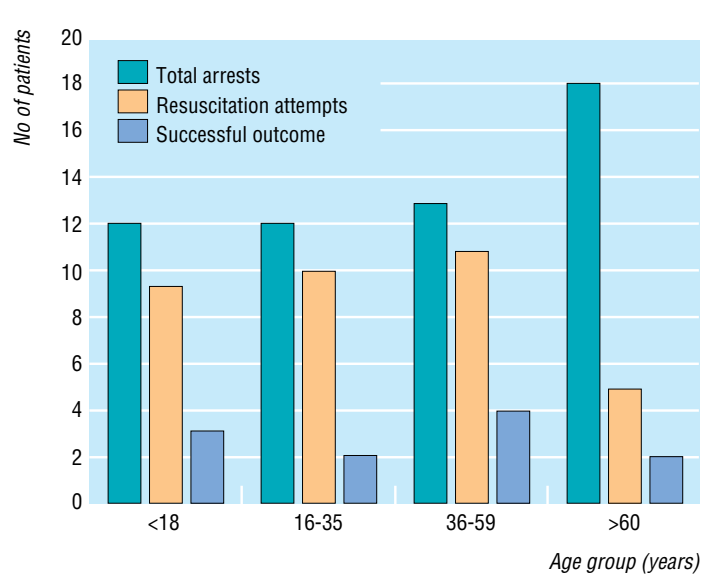

Age related to outcome of cardiopulmonary resuscitation in British television medical dramas

Set in a provincial district general hospital, it portrays the insiders' view of hospital life. The humour is frequently black or offbeat, the stories focusing on the trials and joys of the lives of the often irreverent junior doctors. Ethical and political issues are dealt with uncompromisingly and a wide range of clinical conditions are dealt with realistically.

Medics (Granada) is set in a teaching hospital. A wide range of medical and surgical emergencies are portrayed. Each episode attracts about 8 million viewers.

\section{Results}

The number of arrests, number of resuscitation attempts, and subsequent survival rates for each programme are shown in table 1. A total of 52 on-screen cardiac arrests occurred in 40 of the 64 programmes reviewed. Overall $32(62 \%)$ of these patients were subjected to a resuscitation attempt. The short term success rate was $25 \%$ ( 8 of 32 patients). Three respiratory arrests required ventilatory support alone; all of these patients survived through resuscitation.

The number of arrests (cardiac and respiratory), number of resuscitation attempts, and success rates in four age groups are shown in the figure. Forty four per cent of arrests $(24 / 55)$ occurred in patients aged under $36 ; 33 \%(18 / 55)$ occurred in patients aged over 60 . For patients under 60 years, resuscitation was attempted on four fifths of patients $(81 \% ; 30 / 37)$; for the over 60 age group, the rate was $28 \%(5 / 18)$. Survival through resuscitation was similar in all age groups, ranging from $20 \%$ to $40 \%$.

Although the most common primary reason for resuscitation seemed to be a cardiac disorder (table 2), the causes of the arrests varied: $58 \%(32 / 55)$ of patients collapsed as a result of "medical" illnesses (myocardial infarction, respiratory failure, cancer, aortic aneurysm, 
Table 2 Causes of cardiovascular and respiratory arrests in 64 British television medical dramas

\begin{tabular}{|c|c|c|c|}
\hline Cause of arrest & $\begin{array}{c}\text { No }(\%) \text { of } \\
\text { arrests }\left(n=55^{\star}\right)\end{array}$ & $\begin{array}{l}\text { No }(\%) \text { of resuscitation } \\
\text { attempts }\left(n=35^{\star}\right)\end{array}$ & $\begin{array}{l}\text { No }(\%) \text { of survivors through } \\
\text { resuscitation }\left(n=11^{*}\right)\end{array}$ \\
\hline Cardiac & $14(27)$ & $13(93)$ & $4(31)$ \\
\hline Respiratory failure $\dagger$ & $5(9)$ & $2(40)$ & $2(100)$ \\
\hline Cancerł & $6(11)$ & $2(33)$ & 0 \\
\hline Road traffic accident & $8(15)$ & $5(63)$ & 0 \\
\hline Other trauma & $4(8)$ & $3(75)$ & 0 \\
\hline Haemorrhage & $3(6)$ & $2(67)$ & 0 \\
\hline Burns & $4(8)$ & $3(75)$ & $1(33)$ \\
\hline Drowning & $2(4)$ & $2(100)$ & $2(100)$ \\
\hline Poisoning† & $3(6)$ & $3(67)$ & $1(50)$ \\
\hline Cerebrovascular accident $†$ & $3(6)$ & $1(33)$ & $1(100)$ \\
\hline Hanging & $1(2)$ & 0 & - \\
\hline Pneumothorax & $1(2)$ & $1(100)$ & 0 \\
\hline Subarachnoid haemorrhage & $1(2)$ & 0 & - \\
\hline
\end{tabular}

*Includes three respiratory arrests.

tncludes one respiratory arrest, survivor through resuscitation.

$\ddagger$ All in Cardiac Arrest. epistaxis, or cerebrovascular accident), and in the other 23 patients collapse was most often associated with trauma. Few of the patients dying of chronic disease processes, such as chronic obstructive pulmonary disease or cancer, underwent resuscitation attempts.

\section{Discussion}

Cardiopulmonary resuscitation is well suited to dramatisation, being visually interesting and conferring an atmosphere of urgency and excitement to a scene. Its appeal to producers and script writers is readily apparent. In some instances, cardiopulmonary resuscitation seems to be used solely for its dramatic effect, without necessarily being important to the storyline or involving key characters, but creating the impression of a busy medical unit. For example, episodes of both Cardiac Arrest and Casualty opened with the characters in the middle of an unsuccessful resuscitation sequence, thereby immediately creating an intense atmosphere and seizing the attention of the viewer. On other occasions, doctors and nurses struggle together, perhaps in the climax of the story or a subplot, to save the life of a character whom the viewer has got to know over the previous half hour. The atmosphere is highly charged, the activity is mesmerising, and the emotions and skills of the main characters are often tested to their limit and beyond. If, as Turow proposes, television medical dramas are ultimately about power, ${ }^{12}$ then nowhere is the power of doctor-heroes over life and death so visible. This study confirms that cardiopulmonary resuscitation is a common feature of television medical dramas and is used in a wide variety of contexts and clinical situations.

There has been much discussion and research into the outcome of real life resuscitation attempts, and factors affecting the outcome have been identified. ${ }^{13-17}$ The considerable spread in published survival rates may be attributable to, among other things, varying disease severity, patient selection, differences in the uses of "do not resuscitate" orders, and methodological differences. ${ }^{18}$ The BRESUS group analysed data from a number of British hospitals that might be expected to be comparable with the general hospitals of Casualty, Cardiac Arrest, and Medics and found an overall survival rate of $38 \%$ through the arrest, $28 \%$ at 24 hours, $17 \%$ at discharge from hospital and 13\% at one year. ${ }^{19}$ Subgroups had different outcomes, including out of hospital arrests (20\% survival through arrest and $5 \%$ at one year) and patients with respiratory arrests only (60\% survival through arrests and 18\% at one year).

In this light the survival rate of $25 \%$ in British fictional medical television drama seems to be realistic. Most resuscitation scenes took place in the accident and emergency department or acute ward, and although survival to discharge or beyond may have been implied, it was generally not known. This survival rate is comparable to those found by the BRESUS group for survival through arrest, and the rate of survival to 24 hours, but does not represent longer term survival. However, the patients portrayed in the programmes in this study differ from a representative sample of patients encountered in real life: $54 \%$ $(19 / 35)$ of the patients undergoing resuscitation in television dramas were aged under 36, compared with $6 \%(213 / 3558)$ under 35 in the BRESUS study. In this age group $26 \%(5 / 19)$ survived through resuscitation on television, compared with $35 \%(75 / 213)$ in the BRESUS study. Only 14\% (5/35) of the television resuscitation attempts were on subjects aged over 60 , of whom two $(40 \%)$ survived through resuscitation; $58 \%(2064 / 3558)$ of the BRESUS patients were aged over 64, and their survival rate was $36 \%$ (761/2064).

These findings contrast with the results of a review of resuscitation portrayed in the American television medical dramas ER and Chicago Hope, which reports an overoptimistic misrepresentation of the outcome of resuscitation, with an overall survival through resuscitation of $77 \% .^{20}$ When compared with real life experience the American dramas seem to show an inappropriate proportion of children or young adults having cardiac arrests as a result of drowning or trauma, which may skew the survival rate. ${ }^{21}$

The context within which issues around resuscitation are shown on television will affect how the viewer perceives the events, and this is not fully explored by our study. For example, in one episode of Casualty the resuscitation of an elderly woman who had had a "massive" stroke is interrupted by relatives claiming that she had a living will stating that she did not wish to be subjected to life prolonging treatment in the event of permanent mental incapacity. The ensuing discussions clearly show the dilemmas facing medics and family in such circumstances. The average television viewer is exposed to a wide variety of television medical images, of which the programmes under study here are but a small part. News programmes, documentaries, other dramas and films all frequently portray cardiopulmonary resuscitation, and may have an equivalent or greater influence than the dramas we have studied. Indeed, the American series Baywatch is one of the most watched television programmes in the world, and, we are told, frequently features resuscitation, which is nearly always successful.

Television has potential for strongly influencing patients' knowledge and attitudes. Although the overall rate of success of resuscitation shown on British television is realistic, the pattern of events leading to the 
Key messages

- A quarter of patients in British television medical dramas who received cardiopulmonary resuscitation on screen seemed to survive

- This figure is comparable to initial survival rates in a series of patients in real life

- Patients on television are more likely to suffer cardiac arrest as a result of trauma than in real life, and patients undergoing resuscitation are likely to be younger than patients in real life

- The overall survival rate of patients after cardiopulmonary resuscitation in British television medical drama seems to be more realistic than in American medical dramas

need for resuscitation does not concur with the BRESUS study. Those healthcare workers who talk to patients about resuscitation and who teach resuscitation to professionals and lay people need to take into account the influence of the media on the public's preconceived ideas about the efficacy and outcome of resuscitation.

We thank Karen Wilson (World Productions), Suzi Brown (Granada), and Christine Harmer-Brown (BBC).

Contributors: SW and PGL initiated the project and devised the method. PNG and SW watched the programmes and collected and analysed the data. PNG wrote the paper, which was edited by SW and PGL. PGL will act as guarantor.

Funding: None.

Conflict of interest: None.

1 Kouwenhoven WB, Jude JR, Knickerbocker GG. Closed-chest cardiac massage. JAMA 1960;173:1064-7.
2 Jude JR, Kouwenhoven WB, Knickerbocker GG. Cardiac arrest: report of the application of external cardiac massage in 118 patients. JAMA 1962;178:1063-78

3 Florin D. 'Do not resuscitate' orders: the need for a policy. J $R$ Coll Phys Lond 1993;27:135-8.

4 Hill ME, Macquillan G, Forsyth M, Heath DA. Cardiopulmonary resuscitation: who makes the decision? BMJ 1994;308:1677

5 Liddle J, Gilleard C, Neil A. The views of elderly patients and their relatives on cardiopulmonary resuscitation. I $R$ Coll Phys Lond 1994;28:228-9.

6 Schonwetter RS, Walker RM, Kramer DR, Robinson BE. Resuscitation decision making in the elderly. J Gen Intern Med 1993;8:295-300.

7 Wagg A, Kinirons M, Stewart K. Cardiopulmonary resuscitation: doctors and nurses expect too much. J R Coll Phys Lond 1995;29:20-2.

8 Murphy DJ, Burrows D, Santilli S, Kemp AW, Tenner S, Kreling B, et al. The influence of the probability of survival on patients' preferences regarding cardiopulmonary resuscitation. $N$ Engl J Med 1994;330:545-9.

9 Heap MJ, Munglani R, Klinck JR, Males AG. Elderly people's preferences concerning life-support treatment. Anaesthesia 1993;48:1027-33.

10 Mead GE, Turnbull CJ. Cardiopulmonary resuscitation in the elderly: patients' and relatives' views. J Med Ethics 1995;21:39-44.

11 Schonwetter RS, Teasdale TA, Taffet G, Robinson BE, Luchi RJ. Educating the elderly: cardiopulmonary resuscitation decisions before and after intervention. J Am Geriatr Soc 1991;39:372-7.

12 Turow J. Television entertainment and the US health-care debate. Lancel 1996;347:1240-3

13 Taffet GE, Teasdale TA, Luchi RJ. In-hospital cardiopulmonary resuscitation. JAMA 1998;260:2069-72.

14 Bedell SE, Delbanco TL, Cook EF, Epstein FH. Survival after cardiopulmonary resuscitation in the hospital. $N$ Engl $J$ Med 1983;309:569-76.

15 Murphy DJ, Murray AM, Robinson BE, Campion EW. Outcomes of cardiopulmonary resuscitation in the elderly. Ann Intern Med 1989;111:199-205.

16 Ekström L, Herlitz J, Wennerblom B, Axelsson Å, Bång A, Holmberg S. Survival after cardiac arrest outside hospital over a 12-year period in Gothenburg. Resuscitation 1994;27:181-7.

17 Valentin A, Karnik R, Donath P, Winkler WB, Slany J. Outcome of cardiopulmonary resuscitation in hospitalised patients. Resuscitation 1995;30:217-21

18 Ballew KA, Philbrick JT. Causes of variation in reported in-hospital CPR survival: a critical review. Resuscitation 1995;30:203-15.

19 Tunstall-Pedoe H, Bailey L, Chamberlain DA, Marsden AK, Ward ME, Zideman DA. Survey of 3765 cardiopulmonary resuscitations in British hospitals (the BRESUS study): methods and overall results. $B M J$ 1992:304:1347-51

20 Diem SJ, Lantos JD, Tulsky JA. Cardiopulmonary resuscitation on television. Miracles and misinformation. N Engl J Med 1996;334:1578-82.

21 Markert RJ, Saklayen MG. Cardiopulmonary resuscitation on television. N Engl J Med 1996;335:1605.

\section{A lesson learnt Never again}

It was my first month as a house officer. I was working in the busiest firm of a general surgical department of the teaching hospital from where I had graduated. The firm was headed by a senior professor who was famous both for his surgical skills and gentle nature. Being a fresh trainee I had just started learning to cope with my clinical duties. One afternoon my registrar admitted a young student for an operation on the following day. As our college was attached to a university, we often used to treat students with minor surgical problems. Many of them were not good at adhering to hospital discipline and this one was no exception. I went to take the clinical details twice but he was not to be found in the bed. As he was not in for any major operation I left him to be seen the following day. The next morning the professor came for the routine preoperative ward round. Having sorted out all other patients I was expecting it to go smoothly. This time the said patient was there waiting for us. "What is the diagnosis," inquired the professor. "Left sided varicocele," the registrar replied. "Any abdominal findings?" was the next question. "Nil," said the registrar. "What is his blood pressure like?" This query was directed to me. "Normal," I lied, thinking that I would be considered careless if I said that I had not checked it. "Can I have the sphygmomanometer?" the professor asked the nurse, and suddenly I felt shocked realising that I might get caught. I started to calm down thinking that for a young man in his early 20 s the pressure would probably be normal. The professor checked it himself and asked me to do the same. To my greatest surprise it was 140/92. The professor asked the registrar to arrange for an abdominal ultrasound, which I later found showed a renal cyst. With a mixed feeling of guilt, frustration, and shame I was preparing myself for the worst possible scolding of my life. However the attitude of the professor had more effect on me than his words. "Had you checked it?" he asked. "No," I admitted. Looking at me he said politely, "Never again" and moved to the next patient.

Dawar Abbas, senior house officer in orthopaedics, Dudley

We welcome articles up to 600 words on topics such as A memorable patient, A paper that changed my practice, My most unfortunate mistake, or any other piece conveying instruction, pathos, or humour. If possible the article should be supplied on a disk. Permission is needed from the patient or a relative if an identifiable patient is referred to. We also welcome contributions for "Endpieces," consisting of quotations of up to 80 words (but most are considerably shorter) from any source, ancient or modern, which have appealed to the reader. 